\title{
LIFE CYCLE ASSESSMENT OF LEAFY VEGETABLE CONSUMPTION IN URBAN TAIPEI, TAIWAN
}

\author{
MING-HWI YAO ${ }^{1}$, HUU-SHENG LUR $^{2}$ \& CHUN-HSIANG HUANG $^{2}$ \\ ${ }^{1}$ Agriculture Research Institute, Council of Agriculture, Taiwan \\ ${ }^{2}$ National Taiwan University, Taiwan
}

\begin{abstract}
In recent years, due to economic development and urbanization, a stable supply of food resources has become a major factor in maintaining normal urban metabolism. However, urban expansion entails a reduction in the cultivable area and a reduced agricultural workforce. Thus, urban areas rely on rural areas for food supply. In this research, Taipei (Taiwan) was selected for investigating changes in the sources of leafy vegetables and the effect of such changes on the environment. The "life cycle assessment (LCA)" method was used to evaluate the effect of different origin-to-destination distances on the environment. The results demonstrated that increased transport distances not only increased energy consumption but also increased the effect on the environment, specifically with respect to the carbon footprint, eutrophication, and acidification. Furthermore, different cultivation methods, including protected, open-field, organic, and conventional cultivation, were compared to determine their environmental effects. The results indicated that the conventional cultivation method increased the carbon footprint by 15 times and energy consumption by 22 times compared with the organic cultivation method. Chemical fertilizer use in conventional cultivation is the main driver of this difference. Moreover, the protected cultivation method exhibited a 10-20 times higher impact on the environment than open-field cultivation for all the indicators in the life cycle assessment, of which its acidification index score was the most seriously problematic. Therefore, urban agriculture and organic cultivation could be promoted to make the best use of the limited land supply in the city and increase the self-sufficiency rate of leafy vegetables cultivation in urban areas and reduce the environmental impact caused by transportation and chemical fertilizer use.

Keywords: urbanization, urban metabolism, life cycle assessment, organic cultivation.
\end{abstract}

\section{INTRODUCTION}

As market economies develop, cities provide numerous employment opportunities, and hence, rural populations migrate to cities to make a living; this gradually increases the degree of urbanization. Urbanization across the world began to increase rapidly in the 20th century. In 1900, 1950, and 2000, the degree of global urbanization was $16.4 \%, 29.1 \%$, and $46.8 \%$, respectively. In 2007, the global urban population exceeded the rural population. Furthermore, the degree of global urbanization reached $54.8 \%$ in 2017. It is estimated that by $2050,68 \%$ of the world's population will live in urban areas, and few countries are expected to have larger rural populations than urban populations [1].

Urban metabolism is mainly used to analyze models of matter and energy flow in urban metabolic processes. Wolman [2] suggested that cities are like ecosystems and described how matter and energy flow into the system, similar to how organisms in the ecosystem consume resources, such as sunlight and food, and produce products and waste. When the metabolic system is unable to obtain the resources needed for its internal operation, it must obtain resources from the external environment to support the normal operation of the metabolic system, or it will cause urban metabolic disorders. For example, when a city grows too fast, its managers are unable to maintain control over its various aspects, and thus resource depletion, environmental pollution, ecological damage, and other problems become increasingly prominent. The fundamental reason for these problems is urban metabolic disorder [2], [3]. 
Crop cultivation methods can be classified as open-field cultivation and protected culture. In open-field cultivation, crops are grown under natural conditions, allowing large-scale planting and low-cost production. However, many problems must be overcome in open-field cultivation; tasks to overcome problems include ensuring crop quality, minimizing the harmful effects of pests and diseases, decreasing the susceptibility of crops to weather events or climate shifts, and overcoming the inconvenient regulation of the production period. Protected cultivation can overcome the disadvantages of open-field cultivation. In protected cultivation, fresh weight, dry weight, leaf number, and chlorophyll content of leafy vegetables can be increased, thus enhancing yield [4], [5]. However, the production cost of protected cultivation is much higher than that of open-field cultivation; such costs include capital used to construct facilities, the replacement cost of consumables such as plastic cloth, and the energy cost of lamps inside greenhouses. Although the cost of protected cultivation is high, it is a crucial aspect of the food supply chain because it can hedge against food stock disruptions caused by natural disasters and thus provides a stable food supply.

The management methods of crop cultivation can be divided into conventional and organic cultivation methods. The aim of organic agriculture is to augment ecological processes that foster plant nutrition while protecting soil and water resources from damage [6]. Compared with conventional cultivation, organic agriculture is thought to have a less negative impact on the environment because it does not involve the use of chemical fertilizers, synthetic herbicides, or pesticides. Moreover, organic cultivation can enhance the quality of soil, air, and water and also positively affect biodiversity [7]. However, although organic cultivation has a low impact on the environment, its crop yield is usually lower than that of conventional cultivation. The yields of organic cultivation are on average $80 \%$ those of conventional cultivation. Therefore, the land required to produce the same amount of food in organic farming systems is usually more than that required in conventional farming [8], [9].

In 2018, the degree of urbanization in Taiwan was $79.5 \%$, and the Taipei metropolitan area had the highest urban population density. Therefore, as the population has grown, the area available for leafy vegetables cultivation in Taipei has gradually decreased, but the demand for leafy crops has gradually increased. Thus, the development of urban agriculture may be necessary and could help in the cultivation of leafy vegetables with a short growth cycle, which is not only cheap but also increased quantities of produce to meet the needs of the people [10].

The impact of food on climate change is divided into two aspects: food production and transportation. The transportation makes a small part of the greenhouse gas emissions created by food; $83 \%$ of overall emissions of $\mathrm{CO}_{2}$ are in production phases [11]. However, "Food miles" is a course indicator of the Greenhouse Gas (GHG) contributions of food transportation. The term "food miles" refers to the distance food travels from farm to consumer. With an increase in the distance that food travels, energy consumption is increased as well as carbon emissions [12]. Taipei metropolitan is the most urbanized area in Taiwan, and food is mostly imported from outside due to insufficient leafy vegetables cultivation area. Therefore, this study also explores the differences in environmental impact under different transportation distances. In addition, to minimize the impact on the environment, the concept of "local food" has been proposed for application in sustainable agriculture and alternative food systems [13]. Local food is considered one means of reducing food mileage.

In summary, this study selected the Taipei metropolitan area of Taiwan, which has the highest degree of urbanization of any city in Taiwan, as the research target and used statistics from government units and the Taipei Fruits \& Vegetables Wholesale Market to calculate changes in leafy vegetables production and sources in the Taipei metropolitan area. Furthermore, the method of life cycle assessment (LCA) can be used to assess the integrated environmental impact of the supply chain and of different fields by analyzing a product's 
(commodity/services) entire life cycle. In an environmental assessment, the impact categories are the main issues discussed; the carbon footprint, acidification, eutrophication, and energy consumption are the main environmental impact indicators, of which eutrophication is mainly caused by fertilizer application during the food production. Then, the impact on the environment is assessed according to space and time; finally, data and findings can inform decision-makers [14]. Therefore, the field survey data were analyzed using the LCA method to assess the different environmental impacts of leafy vegetables in Taiwan produced under different methods of crop cultivation and management and involving different distances of delivery to the Taipei Fruits and Vegetables Wholesale Market, and these data can be used as a basis to solve environmental problem in the future.

\section{RESEARCH METHOD}

\subsection{Analysis of statistical data integration}

In the study, we focused our analysis on Taipei, the most urbanized area in Taiwan. According to government unit statistics, the changes in the yield, consumption, and cultivation areas in the Taipei metropolitan area were calculated for the past 30 years. Furthermore, statistical data were used to calculate the space dedicated to leafy vegetables in each area, and the geographic information system (GIS) map was drawn using ArcMap 10.1 to analyze the distribution of the cultivation of leafy vegetables in Taiwan. Additionally, using the statistical data of Taipei Agricultural Products Marketing Corporation, the distribution ratio of leafy vegetables in the Taipei metropolitan area was calculated.

\subsubsection{Life cycle assessment}

In the study, SimaPro (v 8.4.0.0) was used for LCA of the environmental impact of different cultivation systems, management methods, and transportation distances. The main impact factors assessed were the carbon footprint of greenhouse gas emissions, eutrophication and acidification of water resources and soil caused by irrigation and fertilizers, and nonrenewable energy consumption. In addition, the IMPACT 2002+ V2.12 method was used in SimaPro to estimate the impact index (\%).

2.1.2 Life cycle assessment of leafy vegetables from open-field and protected cultivation The LCA of different cultivation systems starts from the 2 aspects of crop cultivation and facilities. Because the life of facilities is usually 10 to 20 years, an independent inventory must be conducted. The structural components of the growing system primarily consist of steel brackets and plastic sheeting, so our analysis focused on these two items. Steel brackets are used for fixing and a plastic sheet is used for protection in these facilities, and the crops produced are mainly leafy vegetables. The amount of fertilizer used during planting and the energy consumption of the production process were estimated, including energy used for agricultural machinery in land preparation, trenching, fertilizing, and spraying tasks. The energy consumption of agricultural machinery is generally diesel fuel, and the energy unit is expressed in the megajoule (MJ).

\subsubsection{Life cycle assessment of leafy vegetables from organic and conventional cultivation}

The biggest difference between organic and conventional cultivation is the application of different fertilizers; the remaining processes are subtly different. The amount of fertilizer used during planting and energy consumption under two different management methods were evaluated. Fertilizer application and the use of agricultural machinery and irrigation pumps in the cultivation process generally use diesel fuel for energy, and the energy unit is expressed 
in MJ. Additionally, in this study, the results of the environmental impacts of different fertilizer sources were evaluated using the parameters built into SimaPro.

\subsubsection{Life cycle assessment of transportation distance}

In this study, we focused on the Taipei metropolitan area and took stock of the environmental impact and cost of transporting leafy vegetables to the Taipei Fruits \& Vegetables Wholesale Market from different origins. It was assumed that the leafy crops are transported by 2.4-ton trucks using diesel as the energy source. The distance between the main production areas of each county and the Taipei Fruits \& Vegetables Wholesale Market was measured using Google Maps and used as the transportation distance for LCA.

\subsubsection{Assessment of environmental impact indicators during crop cultivation}

In the crop cultivation process, the environmental impact at different stages is not the same. In this study, the four factors that cause an environmental impact are seedling raising, fertilizer use, land preparation (oil consumption by traction machines, cultivators, etc.), and power facilities (electricity consumption by irrigation equipment, etc.) which are used to assess differences in indicators of the carbon footprint, eutrophication, acidification, and energy consumption at each cultivation stage.

\section{RESULTS}

\subsection{Urbanization rate and leafy vegetables supply chain of the Taipei metropolitan area}

\subsubsection{Leafy vegetables supply chain of the Taipei metropolitan area}

Changes in the yield, consumption, and areas of leafy crop cultivation in the Taipei metropolitan area over the past 30 years, determined through analysis of statistical data, are shown in Fig. 1. In 2018, the total area and output of leafy vegetables in Taiwan were 30,948 hectares and 890,000 metric tons, respectively. This study selected 3 regions and analyzed their areas of leafy vegetables cultivation by using the GIS (Fig. 2), and the yields of the three cultivation areas accounted for $35.9 \%, 11.7 \%$, and $9.2 \%$, whereas the remaining areas accounted for $43.2 \%$ (Fig. 3(a)). Furthermore, using the statistical data from the Taipei Fruit \& Vegetables Wholesale Market, the proportion of leafy vegetables transported from three areas to the Taipei metropolitan area was calculated (Fig. 3(b)).

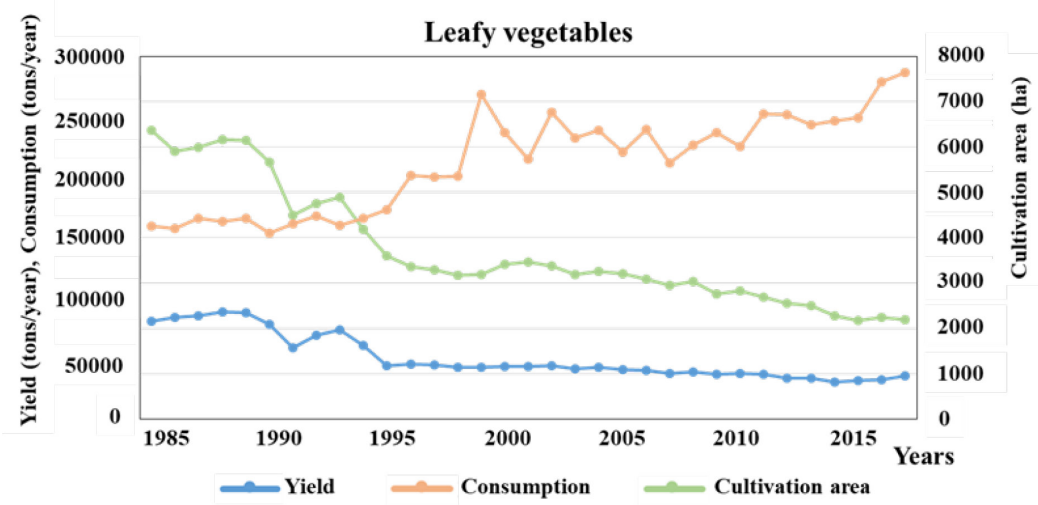

Figure 1: Changes in the yield, consumption, and cultivation area of leafy crops in the Taipei metropolitan area over the past 30 years. 


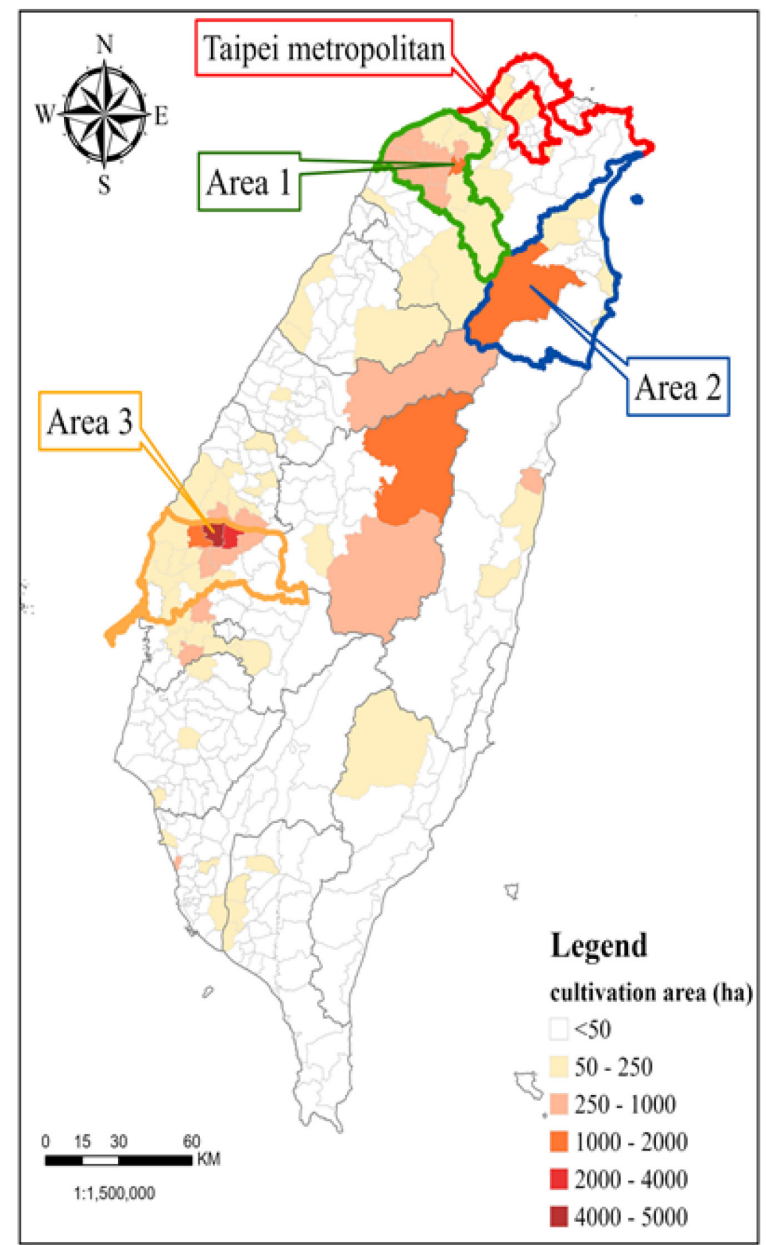

Figure 2: Cultivation areas of leafy vegetables in Taiwan in 2018.

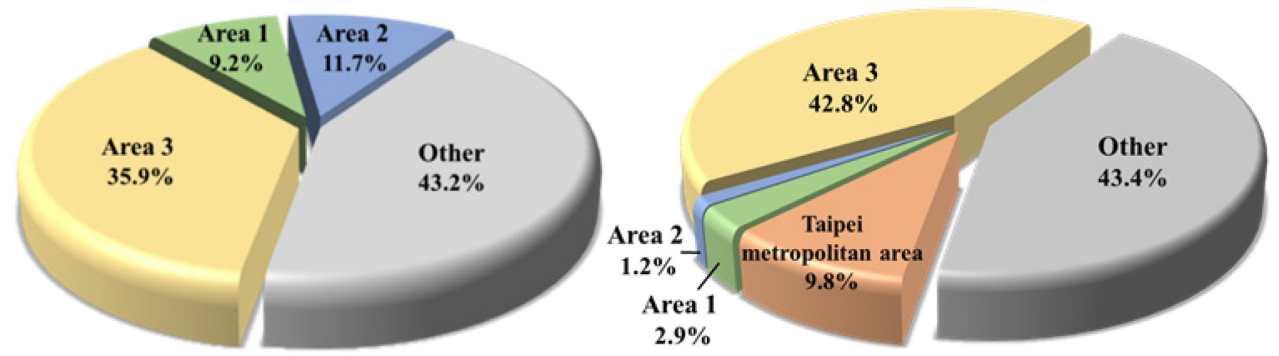

Figure 3: (a) The proportion of leafy vegetables production in Taiwan in 2018; (b) The proportion of leafy vegetables transported from three areas to the Taipei metropolitan area in 2018. 
3.1.2 Environmental impact of different transportation distances

In this study, the Taipei Fruit \& Vegetables Wholesale Market was the destination, and three areas of leafy vegetables cultivation were selected for assessment; these areas are referred to as Area 1, Area 2, and Area 3, and the distances of these areas from the Taipei Fruit \& Vegetables Wholesale Market are 39.9, 105.5, and $214 \mathrm{~km}$, respectively. The total volume transported from the 3 areas in 2018 was $5.64 \mathrm{E}+06,2.31 \mathrm{E}+06$, and $8.46 \mathrm{E}+07 \mathrm{~kg}$, and the typical transportation vehicle was a 2.4-ton truck. After conversion, the fuel consumption per kilogram of vegetables transportation in the 3 areas was $0.4,1.1$, and $2.3 \mathrm{~mL} / \mathrm{kg}$. Thus, the freight mileage (ton $/ \mathrm{km}$ ) of the environmental impact of leafy vegetables transported from three areas to the Taipei Fruit \& Vegetables Wholesale Market are shown in Table 1.

Table 1: Environmental impact of different transportation distances.

\begin{tabular}{|l|c|c|c|c|}
\hline Indicators & Unit & Area 1 & Area 2 & Area 3 \\
\hline Carbon footprint & $\mathrm{kg} \mathrm{CO}_{2 \mathrm{eq}}$ & $4.32 \mathrm{E}-03$ & $1.14 \mathrm{E}-02$ & $2.32 \mathrm{E}-02$ \\
\hline Acidification & $\mathrm{kg} \mathrm{SO}_{2 \mathrm{eq}}$ & $2.87 \mathrm{E}-05$ & $7.58 \mathrm{E}-05$ & $1.54 \mathrm{E}-04$ \\
\hline Eutrophication & $\mathrm{kg} \mathrm{PO}_{4} \mathrm{p}-\mathrm{lim}$ & $3.83 \mathrm{E}-08$ & $1.01 \mathrm{E}-07$ & $2.05 \mathrm{E}-07$ \\
\hline Energy & $\mathrm{MJ}$ & $6.67 \mathrm{E}-02$ & $1.76 \mathrm{E}-01$ & $3.58 \mathrm{E}-01$ \\
\hline
\end{tabular}

3.2 Comparison and contrast of cultivation systems

3.2.1 The proportion of environmental impacts at each stage of crop cultivation

In this study, LCA was used to evaluate the rate of carbon footprint, eutrophication, acidification, and energy consumption caused by various aspects of cultivation, including seedling raising, fertilizer use, land preparation, and power facilities, to understand the environmental impact of each cultivation process. The differences among seedling raising, fertilizer use, land preparation, and powering facilities in terms of environmental impact were shown in Table 2.

Table 2: The proportion of environmental impacts of each part at leafy vegetables cultivation.

\begin{tabular}{|l|c|c|c|c|c|}
\hline Indicators & Unit & $\begin{array}{c}\text { Seedling } \\
\text { raising }\end{array}$ & $\begin{array}{c}\text { Fertilizer } \\
\text { use }\end{array}$ & $\begin{array}{c}\text { Land } \\
\text { preparation }\end{array}$ & $\begin{array}{c}\text { Power } \\
\text { facilities }\end{array}$ \\
\hline Carbon footprint & $\mathrm{kg} \mathrm{CO}_{2 \mathrm{eq}}$ & $8.53 \mathrm{E}-03$ & $6.65 \mathrm{E}-02$ & $7.51 \mathrm{E}-03$ & $3.78 \mathrm{E}-02$ \\
\hline Acidification & $\mathrm{kg} \mathrm{SO}_{2 \mathrm{eq}}$ & $3.31 \mathrm{E}-05$ & $1.30 \mathrm{E}-04$ & $4.99 \mathrm{E}-05$ & $1.47 \mathrm{E}-04$ \\
\hline Eutrophication & $\mathrm{kg} \mathrm{PO}_{4}$ - -lim & $2.28 \mathrm{E}-06$ & $1.15 \mathrm{E}-05$ & $8.03 \mathrm{E}-08$ & $1.01 \mathrm{E}-05$ \\
\hline Energy & $\mathrm{MJ}$ & $1.23 \mathrm{E}-01$ & $1.50 \mathrm{E}+00$ & $1.08 \mathrm{E}-01$ & $5.47 \mathrm{E}-01$ \\
\hline
\end{tabular}

\subsubsection{Differences between leafy vegetables produced under open-field and protected cultivation practices}

The environmental impact of leafy vegetables production under open-field and protected cultivation practices was evaluated on the basis of 1 hectare of cultivation area. The yield, water consumption, and energy consumption of agricultural machinery are shown in Table 3. In addition, in this study, the facility aspect of protected cultivation was calculated independently. In assessing facilities, we used the following values: 31 metric tons of polyvinyl chloride (PVC) plastic sheet and 200 metric tons of steel are required per hectare. The environmental impact of facilities per hectare is shown in Table 4. However, the service life of steel and PVC plastic sheet is approximately 10 years and 5 years, respectively, under 
normal conditions. Therefore, when evaluating the environmental impact index of steel and plastic sheeting in the LCA, the index must be divided by the service life of steel and PVC plastic sheeting. Furthermore, the environmental impact index of facilities was then combined with the environmental impact index of crop cultivation. The differences between open-field and protected cultivation in terms of environmental impact from the production of leafy vegetables per hectare are shown in Table 5; the environmental impact indicators of protected cultivation are approximately 10-20 times higher than those of open-field cultivation.

Table 3: Field survey data from open-field and protected cultivation.

\begin{tabular}{|l|c|c|c|}
\hline Data category & Unit & Open-field & Protected \\
\hline Yields & $\mathrm{kg} / \mathrm{ha}$ & 23,200 & 21,650 \\
\hline Water consumption & $\mathrm{m}^{3} / \mathrm{ha}$ & 2,060 & 1607 \\
\hline Energy consumption & $\mathrm{MJ} / \mathrm{ha}$ & 6,283 & 10,660 \\
\hline
\end{tabular}

Table 4: Environmental impact of facilities.

\begin{tabular}{|l|c|c|c|}
\hline Indicators & Unit & PVC plastic sheet & Steel \\
\hline Carbon footprint & $\mathrm{kg} \mathrm{CO}_{2 \mathrm{eq}}$ & $2.75 \mathrm{E}+00$ & $4.71 \mathrm{E}+00$ \\
\hline Acidification & $\mathrm{kg} \mathrm{SO}_{2 \mathrm{eq}}$ & $1.39 \mathrm{E}-02$ & $2.86 \mathrm{E}-02$ \\
\hline Eutrophication & $\mathrm{kg} \mathrm{PO}_{4} \mathrm{p}-\mathrm{lim}$ & $4.04 \mathrm{E}-04$ & $8.07 \mathrm{E}-04$ \\
\hline Energy & $\mathrm{MJ}$ & $6.81 \mathrm{E}+01$ & $5.46 \mathrm{E}+01$ \\
\hline
\end{tabular}

Table 5: Environmental impact of open-field and protected cultivation.

\begin{tabular}{|l|c|c|c|}
\hline Indicators & Unit & Open-field & Protected \\
\hline Carbon footprint & $\mathrm{kg} \mathrm{CO}_{2 \mathrm{eq}}$ & $1.04 \mathrm{E}-01$ & $1.13 \mathrm{E}+00$ \\
\hline Acidification & $\mathrm{kg} \mathrm{SO}_{2 \mathrm{eq}}$ & $3.27 \mathrm{E}-04$ & $6.06 \mathrm{E}-03$ \\
\hline Eutrophication & $\mathrm{kg} \mathrm{PO}_{4} \mathrm{p}-\mathrm{lim}$ & $2.16 \mathrm{E}-05$ & $1.91 \mathrm{E}-04$ \\
\hline Energy & $\mathrm{MJ}$ & $2.16 \mathrm{E}+00$ & $2.08 \mathrm{E}+01$ \\
\hline
\end{tabular}

\subsubsection{Differences between leafy vegetables produced through organic or conventional} cultivation

The environmental impacts of leafy vegetables produced through organic or conventional cultivation were evaluated on the basis of 1 hectare of cultivation area. The yield, water consumption, fertilizer application, and energy consumption of agricultural machinery are shown in Table 6 . The differences between organic and conventional cultivation in terms of the environmental impact of the production of leafy vegetables per hectare are shown in Table 7, and the results show that the environmental impact indicators of conventional cultivation are approximately 10-20 times higher than those of organic cultivation. In addition, this study also evaluated the environmental impact of pig manure; cow manure; compost from organic fertilizer; and ammonium sulfate, calcium superphosphate, and potassium chloride from chemical fertilizer; these were all measured per kilogram in SimaPro, and the results are shown in Table 8. In addition, in the LCA calculation software, organic fertilizers are identified as being hand-made by their own farms, and are produced by fermentation in the 
natural environment without being processed by machines. Therefore, they presume that organic fertilizers have no impact on the environment, as the environmental impact indicators are displayed "N/A"

Table 6: Field survey data on organic and conventional cultivation.

\begin{tabular}{|l|c|c|c|}
\hline Data category & Unit & Organic & Conventional \\
\hline Yields & $\mathrm{kg} / \mathrm{ha}$ & 22,500 & 23,200 \\
\hline Water consumption & $\mathrm{m}^{3} / \mathrm{ha}$ & 247 & 2,060 \\
\hline Energy consumption & $\mathrm{MJ} / \mathrm{ha}$ & 941.2 & 6,283 \\
\hline Ammonium Sulphate & & & 1,235 \\
\hline Calcium ammonium nitrate & \multirow{3}{*}{$\mathrm{kg} / \mathrm{ha}$} & \multirow{2}{*}{$\mathrm{N} / \mathrm{A}$} & 415 \\
\hline Potassium Chloride & & & 415 \\
\hline \#43 Instant Water Soluble Fertilizer & & & 825 \\
\hline
\end{tabular}

Table 7: Environmental impact of organic and conventional cultivation.

\begin{tabular}{|l|c|c|c|}
\hline Indicators & Unit & Organic & Conventional \\
\hline Carbon footprint & $\mathrm{kg} \mathrm{CO}_{2 \mathrm{eq}}$ & $6.71 \mathrm{E}-03$ & $1.04 \mathrm{E}-01$ \\
\hline Acidification & $\mathrm{kg} \mathrm{SO}_{2 \mathrm{eq}}$ & $2.97 \mathrm{E}-05$ & $3.27 \mathrm{E}-04$ \\
\hline Eutrophication & $\mathrm{kg} \mathrm{PO}_{4} \mathrm{p}-\mathrm{lim}$ & $1.45 \mathrm{E}-06$ & $2.16 \mathrm{E}-05$ \\
\hline Energy & $\mathrm{MJ}$ & $9.69 \mathrm{E}-02$ & $2.16 \mathrm{E}+00$ \\
\hline
\end{tabular}

Table 8: Data on the environmental impact of organic and chemical fertilizer in SimaPro.

\begin{tabular}{|c|c|c|c|c|}
\hline & & \multicolumn{3}{|c|}{ Chemical Fertilizer (kg) } \\
\hline Indicators & Unit & $\begin{array}{c}\text { Ammonium } \\
\text { sulfate }\end{array}$ & $\begin{array}{c}\text { Calcium } \\
\text { superphosphate }\end{array}$ & $\begin{array}{c}\text { Potassium } \\
\text { chloride }\end{array}$ \\
\hline Carbon footprint & $\mathrm{kg} \mathrm{CO} 2 \mathrm{eq}$ & $5.80 \mathrm{E}-01$ & $2.23 \mathrm{E}-01$ & $2.07 \mathrm{E}-01$ \\
\hline Acidification & $\mathrm{kg} \mathrm{SO} \mathrm{eq}_{\mathrm{e}}$ & $1.02 \mathrm{E}-03$ & $1.14 \mathrm{E}-03$ & 3.34E-04 \\
\hline Eutrophication & $\mathrm{kg} \mathrm{PO}_{4}$ p-lim & $1.30 \mathrm{E}-05$ & $5.56 \mathrm{E}-06$ & 4.39E-06 \\
\hline Energy & MJ & $1.58 \mathrm{E}+01$ & $5.94 \mathrm{E}+00$ & $3.63 \mathrm{E}+00$ \\
\hline & & \multicolumn{3}{|c|}{ Organic Fertilizer $(\mathrm{kg})$} \\
\hline Indicators & Unit & Pig manure & Cow manure & Compost \\
\hline Carbon footprint & $\mathrm{kg} \mathrm{CO}_{2 \mathrm{eq}}$ & \multirow{4}{*}{ N/A } & \multirow{4}{*}{$\mathrm{N} / \mathrm{A}$} & \multirow{4}{*}{ N/A } \\
\hline Acidification & $\mathrm{kg} \mathrm{SO} 2 \mathrm{eq}$ & & & \\
\hline Eutrophication & $\mathrm{kg} \mathrm{PO}_{4} \mathrm{p}$-lim & & & \\
\hline Energy & $\mathrm{MJ}$ & & & \\
\hline
\end{tabular}

\section{DISCUSSION}

In Taiwan, limited data are available on the environmental impact of leafy vegetables cultivation and transportation evaluated using LCA. Therefore, this study will establish LCA methods for this part and compare them to explore the differences. 


\subsection{Influence of food miles on environmental impact}

Four basic modes of transporting large quantities of goods are water, railway, road, and aviation. The different modes of transportation result in differences in energy consumption and carbon footprint [11]. Moreover, in addition to transportation methods, transportation distance results in different environmental impacts. Consistent with this study's results (Table 1), another study indicated that when using road transportation methods, the carbon footprint emissions increase as transport distance increases [15]. As mentioned earlier, the greater the energy consumption of the transportation mode and the greater the transportation distance are, the more severe the environmental impact will be. To reduce the negative effects of crop transportation, the concept of urban agriculture has been proposed. The production of food through urban agriculture can reduce the amount of crop transported from a place of origin, thereby reducing food miles and thus reducing greenhouse gas emissions caused by transportation [16].

\subsection{Discussion of the environmental impact of various methods of crop cultivation} and management

Scholars cultivated lettuce under open-field cultivation and protected cultivation practices, using three types of facilities, namely a plastic greenhouse, plastic mulch, and plastic mulch combined with fleece. The scholars evaluated the environmental impact of different cultivation methods, and the results indicated that protected cultivation has a greater impact on the environment than open-field cultivation, and the results are consistent with the present study (Table 5). In addition, as more facility materials are used, the impact on the environment becomes greater [17]. If the facility aspect of protected cultivation is not considered in the LCA, the difference between open-field cultivation and protected cultivation in terms of environmental impact is negligible. The main cause of the environmental impact of protected cultivation is the facility. Therefore, renewable materials or materials with a long service life should be used to reduce the use of consumables and thereby reduce the impact of facilities on the environment [18].

Scholars cultivated lettuce under organic and conventional cultivation and evaluated the differences in the impact on the environment. Indicators of environmental impact were more serious under conventional cultivation than under organic cultivation [19]. The results are consistent with the present study (Table 7). The biggest difference between organic and conventional cultivation is chemical fertilizer use during cultivation. Therefore, the environmental impacts of chemical and organic fertilizers were evaluated using the parameters built into SimaPro, and the results demonstrated that organic fertilizers in the LCA system do not negatively impact the environment (Table 8). Thus, chemical fertilizers are largely responsible for the impact of conventional cultivation on the environment. However, the previous study has pointed out that nitrogen content is the most critical points influencing environmental impact, but the nitrogen emission model often is built on assumptions from conventional agriculture leading to even greater deviances for organic systems between the amount of $\mathrm{N}$ calculated by emission models and the actual amount of $\mathrm{N}$ available for emissions. Therefore, in the future, more representative background data on organic cultivation should be established in the LCA to provide a more accurate assessment of organic agricultural cultivation management [10]. 


\subsection{Local production for local consumption}

In recent years, the concept of Local Production, Local Consumption (LPLC) has become popular. Importing vegetables from remote areas involves large energy consumption due to transportation. Therefore, by using urban space to grow crops to avoid importing from remote areas, energy consumption can be reduced [20]. This research determined that the area for cultivation of leafy vegetables in the Taipei metropolitan area has gradually decreased but the total demand for leafy vegetables by the people has gradually increased (Fig. 2). Thus, to meet local consumption through local production, developing urban agriculture is a good means of increasing yields of leafy vegetables while reducing energy consumption and carbon footprint. However, local production combined with conventional cultivation has a greater impact on the environment than production in remote areas combined with organic cultivation (data not shown). Therefore, it suggested that utilizes local production should combine with organic cultivation to reach the goal of reducing the environmental impacts.

\subsection{Application and positive effects of urban agriculture}

Urban agriculture is a method of implementing agricultural cultivation in or around the city and can overcome food availability problems associated with a large urban population. However, the development of urban agriculture may be limited by other forms of urban development, especially in high-density cities; thus, the concept of rooftop farming has been proposed to solve the problem of insufficient land. Rooftop farming provides several benefits, including food supply, carbon sequestration, stormwater retention, energy savings, and mitigation of the urban heat island effect [16]. Moreover, to produce a large amount of food on limited land, vertical cultivation is a good solution that improves land-use efficiency, increases yield per unit area, and increases crop yield [21]. Through the development of urban agriculture, it is possible to increase crop yields in the urban area to meet the needs of the large population of the city and also to reduce the number of crops transported from origin sites, thereby reducing carbon emissions.

\section{CONCLUSIONS}

With increased urbanization and urban expansion, the areas of leafy vegetables cultivation in the Taipei metropolitan area have gradually decreased but the demand for leafy vegetables has gradually increased. Therefore, to meet people's demand for leafy vegetables in the Taipei metropolitan area, they are imported from other areas to the Taipei metropolitan area. However, this importation from distant production areas results in a severe environmental impact.

In addition, in the process of producing leafy vegetables in various areas, different methods of cultivation and management are used, and each has its advantages and disadvantages. According to this study's results, compared with open-field cultivation and organic cultivation, protected cultivation and conventional cultivation have a greater impact on the environment. However, protected cultivation can shorten the crop cultivation cycle to increase the multiple cropping index and increase yield. Moreover, facilities can protect crops from the impact of natural disasters and stabilize the crop supply.

In summary, if urban agriculture can be developed in Taipei metropolitan area, especially in the form of vertical farming, the limited land supply in the city can be used as much as possible and increase the yield per unit of land. In addition, organic cultivation can also be promoted to replace chemical fertilizers with homemade compost. Through the aforementioned methods, it may be possible to solve the problem of insufficient production areas to increase the self-sufficiency rate of leafy vegetables production in the Taipei metropolitan area and reduce 
the number of crops transported from distant production areas. Therefore, the demand of Taipei metropolitan area for leafy vegetables can be met while reducing the environmental impact caused by the transportation of leafy vegetables and chemical fertilizer use.

\section{ACKNOWLEDGEMENTS}

We thank Professor Fi-John Chang (National Taiwan University) for help with this research. This research (107-2621-M-002-004-MY3) was funded by the Ministry of Science and Technology.

\section{REFERENCES}

[1] Ritchie, H. \& Roser, M., Urbanization. Our World in Data, 2018.

[2] Wolman, A., The metabolism of cities. Scientific American, 213(3), pp. 178-193, 1965.

[3] Zhang, Y., Urban metabolism: A review of research methodologies. Environmental Pollution, 178, pp. 463-473, 2013.

[4] Travieso, L.L., Leon, A.P., Logegaray, V.R. \& Frezza, E.D., Loose leaf lettuce quality grown in two production systems. European Journal of Scientific Research, 12(30), pp. 55-66, 2016.

[5] Carey, E.E., Jett, L., Lamont, W.J., Nennich, T.T., Orzolek, M.D. \& Williams, K.A., Horticultural crop production in high tunnels in the United States: A snapshot. HortTechnology, 19(1), pp. 37-43, 2009.

[6] Pimentel, D., Hepperly, P., Hanson, J., Douds, D. \& Seidel, R., Environmental, energetic, and economic comparisons of organic and conventional farming systems. BioScience, 55(7), pp. 573-582, 2005.

[7] Lorenz, K. \& Lal, R., Environmental impact of organic agriculture. Advances in Agronomy, Elsevier Inc., pp. 99-152, 2016.

[8] De Ponti, T., Rijk, B. \& Van Ittersum, M.K., The crop yield gap between organic and conventional agriculture. Agricultural Systems, 108, pp. 1-9, 2012.

[9] Meier, M.S., Stoessel, F., Jungbluth, N., Juraske, R., Schader, C. \& Stolze, M., Environmental impacts of organic and conventional agricultural products - Are the differences captured by life cycle assessment. Journal of Environmental Management, 149, pp. 193-208, 2015.

[10] De Bon, H., Parrot, L. \& Moustier, P., Sustainable urban agriculture in developing countries. A review. Agronomy for Sustainable Development, 30(1), pp. 21-32, 2010.

[11] Weber, C.L. \& Matthews, H.S., Food-Miles and the Relative Climate Impacts of Food Choices in the United States, 2008.

[12] Saunders, C. \& Barber, A., Carbon footprints, life cycle analysis, food miles: Global trade trends and market issues. Political Science, 60(1), pp. 73-88, 2008.

[13] Lang, T. \& Heasman, M., Food Wars: The Global Battle for Mouths, Minds and Markets, Routledge, 2015.

[14] Chang, D., Lee, C.K.M. \& Chen, C.H., Review of life cycle assessment towards sustainable product development. Journal of Cleaner Production, 83, pp. 48-60, 2014.

[15] Wakeland, W., Cholette, S. \& Venkat, K., Food transportation issues and reducing carbon footprint. Green Technologies in Food Production and Processing, pp. 211236, 2012.

[16] Whittinghill, L.J. \& Rowe, D.B., The role of green roof technology in urban agriculture. Renewable Agriculture and Food Systems, 27(4), pp. 314-322, 2012.

[17] Romero-Gámez, M., Audsley, E. \& Suárez-Rey, E.M., Life cycle assessment of cultivating lettuce and escarole in Spain. Journal of Cleaner Production, 73, pp. 193203, 2014. 
82 Urban Agriculture and City Sustainability II

[18] Anton, A., Montero, J.I., Munoz, P. \& Castells, F., LCA and tomato production in Mediterranean greenhouses. International Journal of Agricultural Resources, Governance and Ecology, 4(2), pp. 102-112, 2005.

[19] Foteinis, S. \& Chatzisymeon, E., Life cycle assessment of organic versus conventional agriculture. A case study of lettuce cultivation in Greece. Journal of Cleaner Production, 112, pp. 2462-2471, 2016.

[20] Hara, Y., Tsuchiya, K., Matsuda, H., Yamamoto, Y. \& Sampei, Y., Quantitative assessment of the Japanese "local production for local consumption" movement: A case study of growth of vegetables in the Osaka city region. Sustainability Science, 8(4), pp. 515-527, 2013.

[21] Eigenbrod, C. \& Gruda, N., Urban vegetable for food security in cities. A review. Agronomy for Sustainable Development, 35(2), pp. 483-498, 2015. 